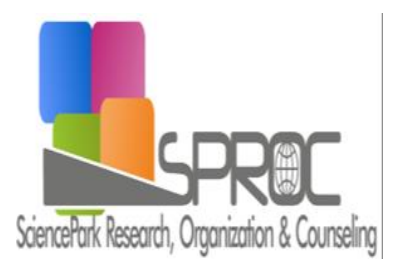

\title{
Location-based games with smartphones - developing a toolbox for educators
}

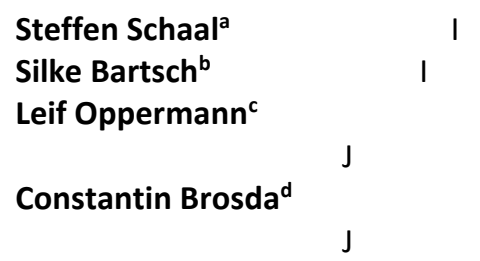

Suggested Citation:

New Trends and Issues Proceedings on Humanities and Social Sciences.

Abstract 
New Trends and Issues Proceedings on Humanities and Social Sciences.

1. Introduction

I

J

J

I

J

J

J

J

J 
New Trends and Issues Proceedings on Humanities and Social Sciences.

2. MILE (move-interact-learn-eat) - a transdisciplinary development project I 
।

I

3. Methods \& Material

3.1 Mobile, location-based games design process for MILE games

I

J

।

। 
Table 1. Requirements review for the (i) design of the authoring system and as (ii) use cases for the native MILE app 


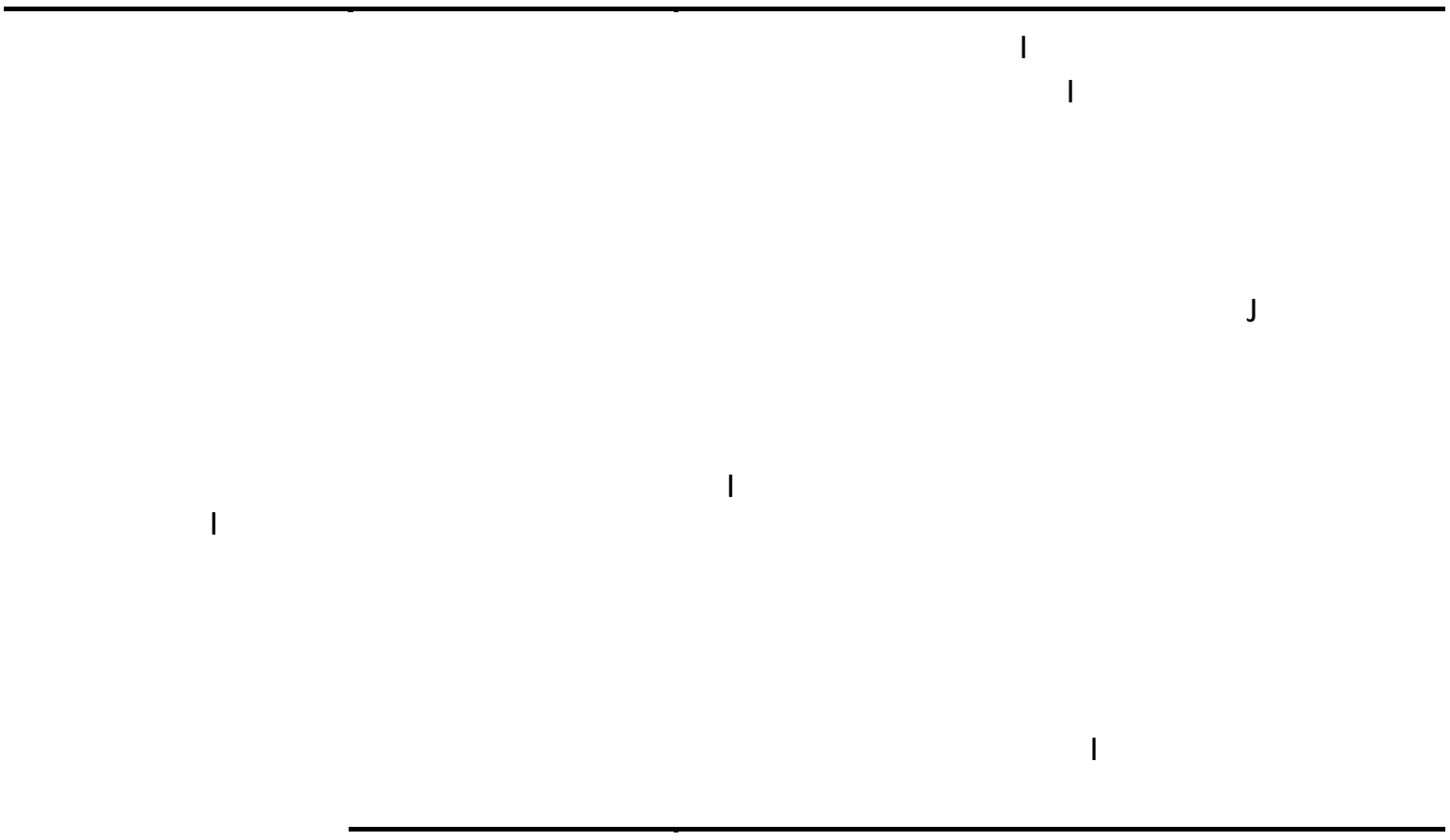

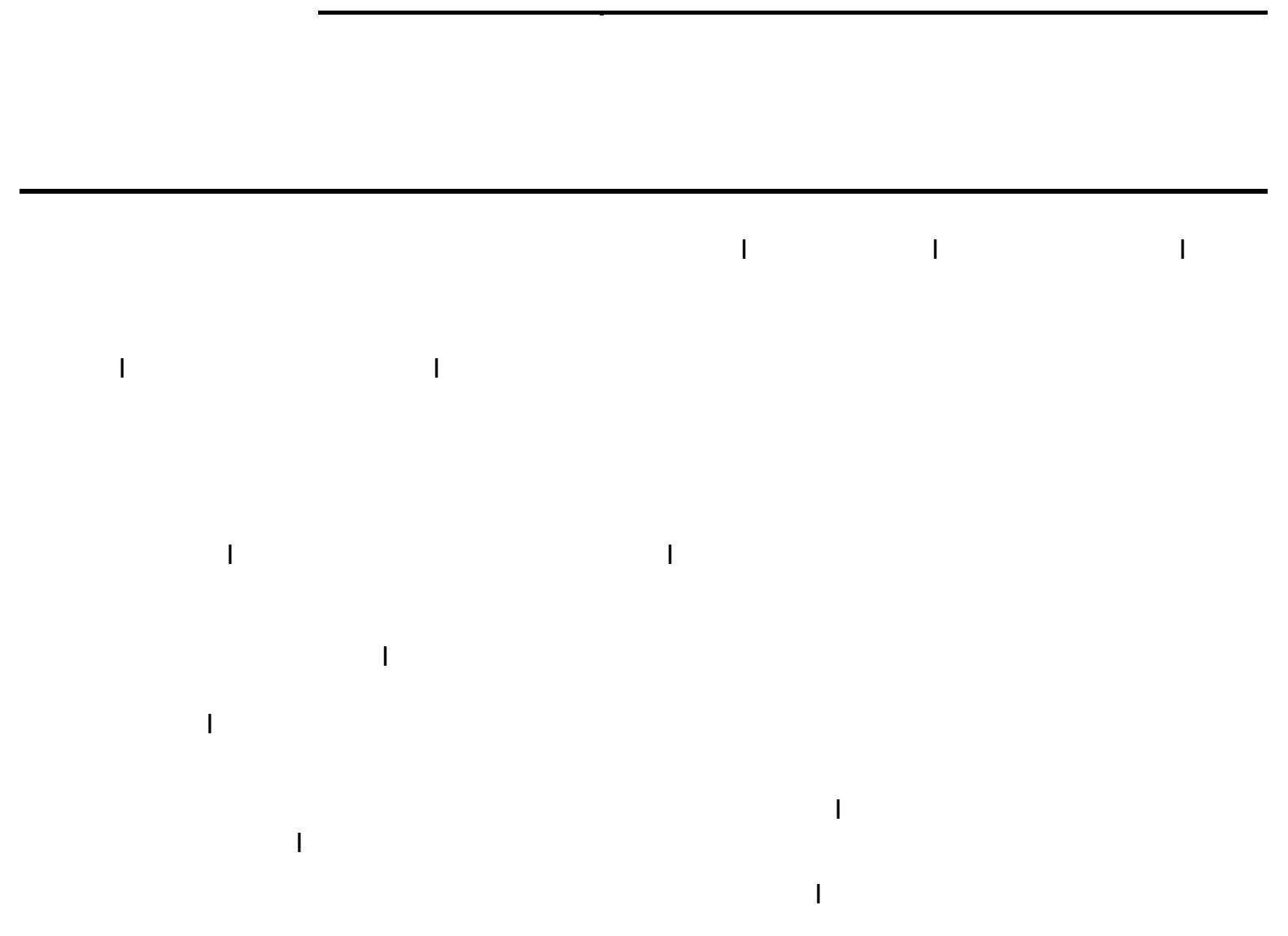




\subsection{Participants}

\subsection{Methods}

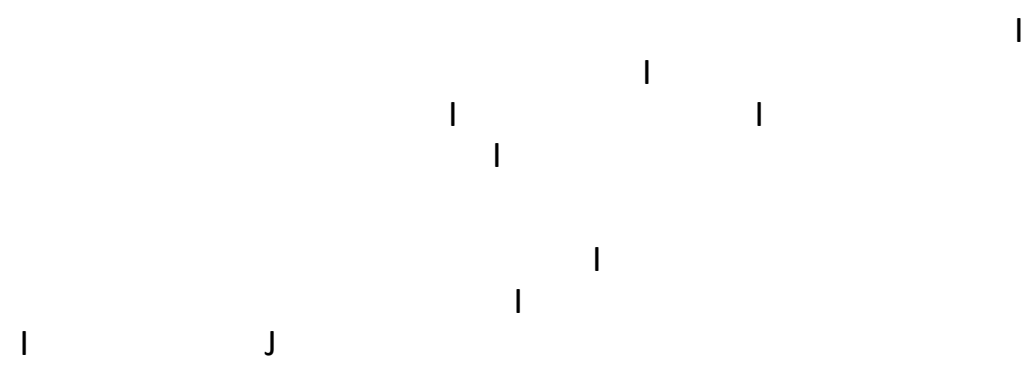

4. Results

4.1 Focus group results

Table 2. Results of the focus group workshop (pooled data from discussion and open questionnaire, $N=11$ participants) 
J J I

J

J

I

I 
I

I

I

5. Discussion and conclusion 


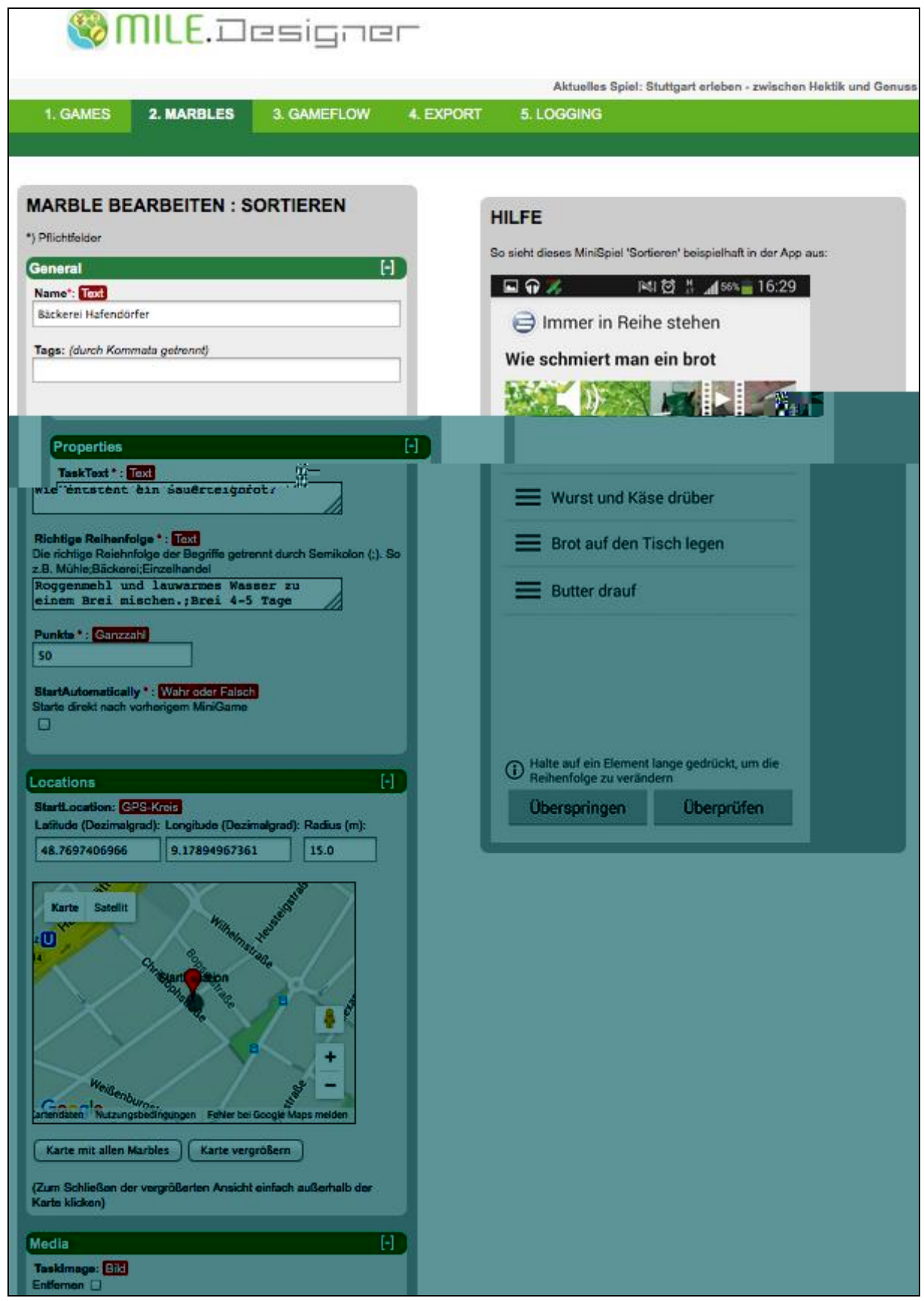

Figure 1. Template of a location-based task. The green tabs represent the workflow of the game design 


\title{
Acknowledgment
}

\section{References}

\author{
Language Learning \& Technology, 18
}

Educational Researcher, 1

November 2010

Social Applications for Lifelong Learning, Patra, Greece, 4-5

Research and Practice in Technology Enhanced Learning, 4

Journal of the Learning Sciences, 13

Jugendesskultur: Bedeutungen des Essens fur Jugendliche im Kontext Familie und Peergroup. Forschung und Praxis der Gesundheitsforderung

Haushalt in Bildung und Forschung, 4

Haushalt in Bildung und Forschung, 3

।

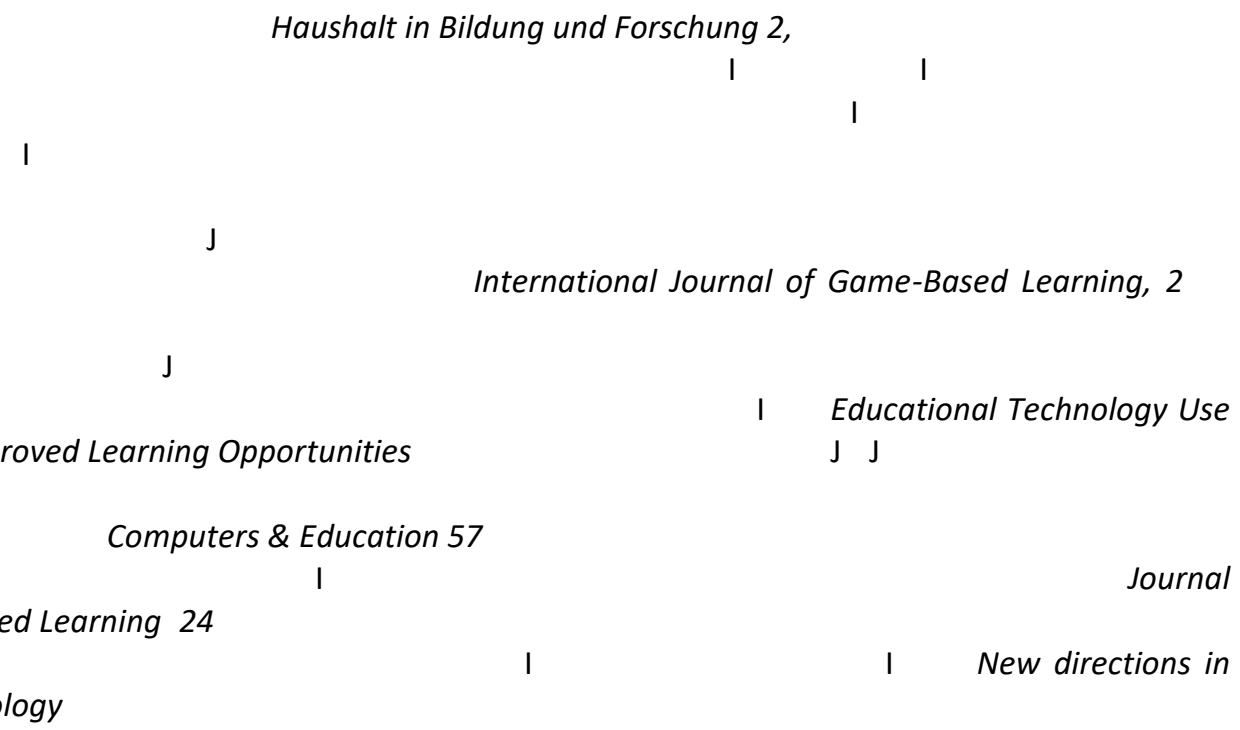

educational technology 
Educational Researcher, 32

Digital cityscapes: Merging digital and urban playspaces

Journal of Teacher Education, 60

Educational Researcher, 32

CSCW'06 Proceedings of the 2006 20th Anniversary Conference on Computer supported cooperative Work

aktuellen Jugendstudien

Konsumkompetenz von Jugendlichen. Ein Uberblick uber Kernaussagen aus

Computers \& Education, 67

$\mathrm{J}$

Business Research 58

$\mathrm{J}$

In proceedings of the 48th Annual Hawaii International Conference on System Sciences

CSCW'96 Proceedings of the 1996 ACM Conference on Computer Supported Cooperative Work

I

।

$\mathrm{J}$

Improve Learning, 54

TechTrends: Linking Research and Practice to

Educational Technology \& Society, 13

Computers \& Education, 55

British Journal of Educational Technology, 1

Zeitschrift Fur E-Learning, 4
$\mathrm{~J}$ Computers and Education 56
। The design and use of simulation computer games in education

23

Computer Assisted Learning

I Situated learning: Legitimate peripheral participation

$\mathrm{J}$

Science

Education and Technology, 6 
$\mathrm{J}$

J International Conference on Mobile Learning

I Proceedings of E-Learn: World Conference on E-Learning in Corporate, Government, Healthcare, and Higher Education 2008

Mobile learning. Structures, agency, practices

I

Computers in the Schools, 31

J

$\mathrm{J}$

and Learning (IMCL), 2014 International Conference

Digital game-based learning J

Interactive Mobile Communication Technologies

\& Behavior, 46

Environment

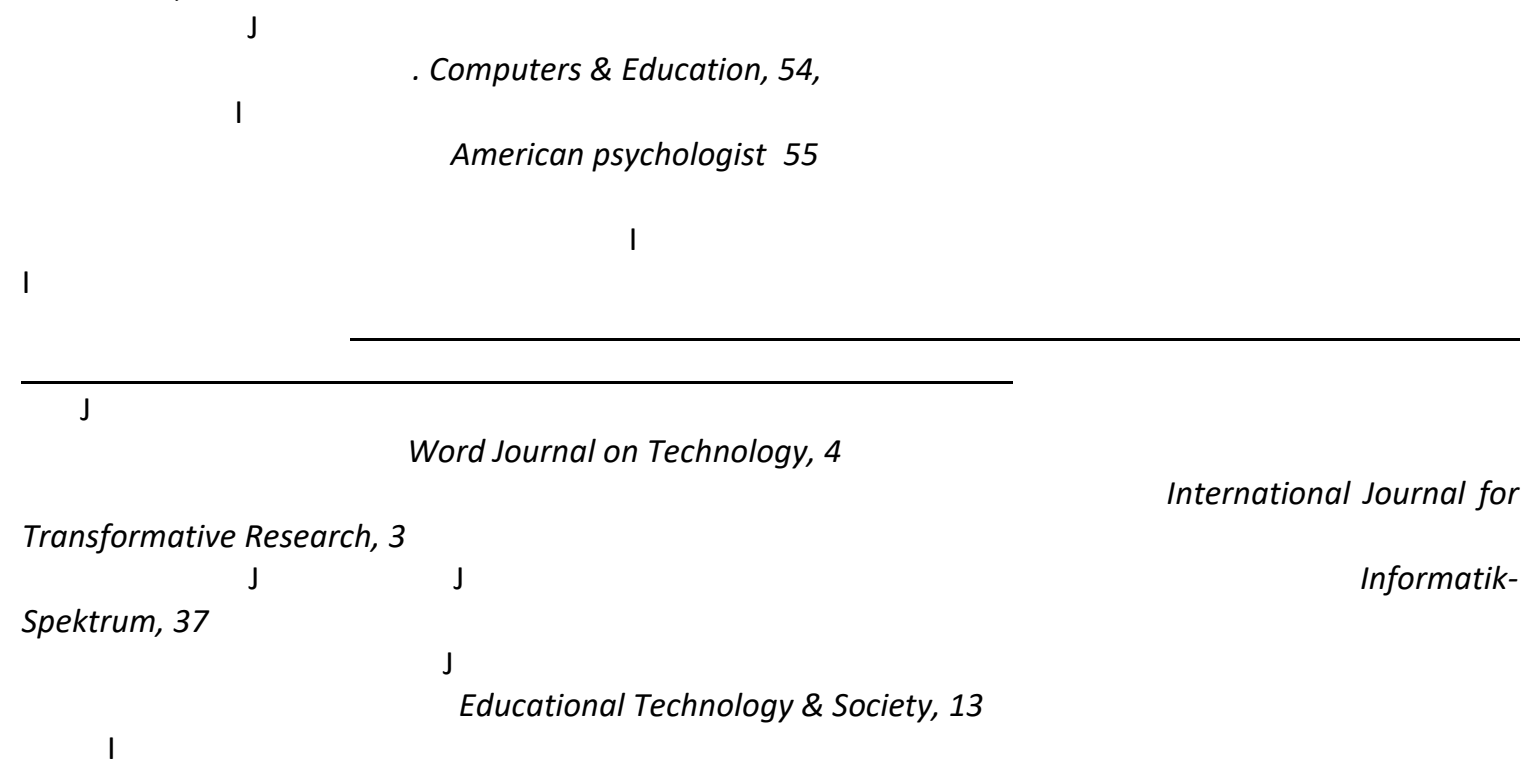

[28.09. 2014, 19: 54]

Verfugbar unter: www. mpfs. de

Proceedings of the 12th International Conference on Mobile and Ubiquitous Multimedia,

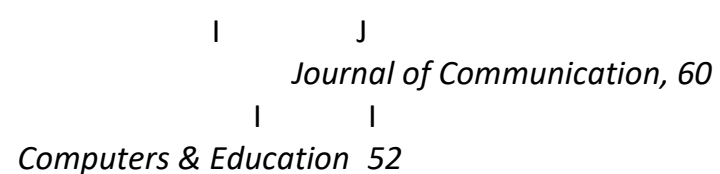


New Trends and Issues Proceedings on Humanities and Social Sciences.

Technologies, GET2012

IADIS International Conference Game and Entertainment

$\mathrm{J}$

Research in Learning Technology,19 